\title{
Logic, psyche and biology
}

\section{Philip Dammen}

The Norwegian State Academy of Music, Oslo, Norway

\section{Email address:}

philip.dammen@nmh.no

\section{To cite this article:}

Philip Dammen. Logic, Psyche and Biology. Psychology and Behavioral Sciences. Vol. 2, No. 3, 2013, pp. 106-111. doi: $10.11648 /$ j.pbs.20130203.14

\begin{abstract}
This article presents a logical analysis of how mentally rooted psychological diseases are constructed and what occurs mentally when a psychological change takes place as a result of treatment. Logical analysis is an approach that can be used to develop a scientific understanding of mentally rooted problems. The experience of mental distress seems to be a result of access to potentially separable and observable mental elements that involve emotions. Mental changes that occur as a result of treatment may be considered to be the result of changes in the accessibility of these mental elements. The mapping of these mental elements, as well as access to and the changing of these mental elements, can be facilitated through treatment. Empirical findings combined with logical analysis make it possible to develop scientific knowledge regarding how mentally experience psychological pain and mental disorders are constructed. This knowledge also makes it possible to develop a scientific and predictable approach to treating mentally rooted disorders and to develop mental states of well-being and skillfulness. The findings of the thesis may therefore be of interest in therapy, education, sports psychology, and performance-focused courses, among other disciplines.
\end{abstract}

Keywords: Mental Rooted Disorders, Mental Elements, Mental Change, Therapy, Logic, Psyche

\section{Introduction}

This article is from a doctoral thesis accepted in 2013, which was a study of psychological distress and mental change as observed via individual change through treatment. The thesis sought to answer the following questions: how are the immediate experience of mental problems constructed mentally, and what occurs psychologically within the patients when they achieve mental changes as a result of treatment? The purpose of this paper is to illustrate the assumption that solving some of the challenges of psychiatry is possible through logical and empirically based argumentation.

This article focuses on the immediate experience of mental pain. In the following the mentally anchored psychological distress and disorders are defined as conditions that can be changed through verbal therapy, whereas somatically rooted psychological disorders are defined as mental conditions that cannot be changed through verbal interventions.

A combined design was applied. Emphasis was placed on the distribution of different types of statements in the conversation between the client and the therapist. Emphasis was also placed on the results that could be traced to the treatment in terms of mental changes. The following methods were used. The first method employed a clinical approach that was inspired by the brief therapy traditions [1-11]. Another approach, inspired by the Grounded Theory ${ }^{12}$, was used to develop the hypothesis of the psyche and to determine the types of statements that should be investigated in the therapy sessions. A quantitative approach with an emphasis on descriptive statistics was used to examine the distribution of the various types of statements between the therapist and client.

Approximately 120 treatments and 720 consultations constitute the empirical basis for the logical analysis described in this article. The results of the analysis resulted in ten hypotheses regarding mental distress as a mental experience and the mental processes that occur when patients experienced psychological changes as a result of treatment ${ }^{[13]}$. The hypotheses that formed the foundation of the logical analysis are omitted here because logical reasoning should be obvious and intuitive and, thus, should not need theoretical justification. The development of the logical analysis was inspired by Wittgenstein's picture theory ${ }^{[14]}$ Popper's theory of falsification ${ }^{[15]}$ and Derrida's concept of deconstruction ${ }^{[16]}$. 


\section{Background}

\subsection{Therapy Results}

Previously observed permanent change as a result of short-term treatment (one to six consultations) led to the desire to understand how mental torment develops as well as what occurs mentally in patients when they achieve changes through therapy. Some example cases are as follows: A young boy with severe posttraumatic stress disorder as a result of violence, who experienced a long stay in hospital, eliminated his mental pain within three consultations after two years of constant anxiety, social isolation, and deteriorating school performance. Previous treatments had not helped. A young woman who was a victim of incest for several years during childhood was cured within five consultations. Previous treatment had not helped. Another client experiencing panic attacks, work-related conflicts, and family problems returned to work after five days of treatment. Actors, dancers, musicians, and managers have received help for performance anxiety in one to three consultations.

All of the patient treatments were conducted using the same methods, with minimal focus on the causes of the mental torment and on the context in which the mental plagues occurred. The treatment was conducted using the client's words and statements as the basis for change. The investigation of this type of experience led to the development of ten different theories about how the mental disorder was constructed as a mental phenomenon and what occurred mentally when the patients achieved psychological improvement through treatment. Later, I discovered that most of these theories could be derived through a logical argument.

\subsection{Challenges in Psychiatry}

There is a lack of sufficient scientific knowledge in the field of psychiatry regarding how the psychological disorders are constructed, and about what occurs mentally when there is a change as a result of treatment is also lacking. No methods currently exist in the fields of psychology to precisely observe when in the therapeutic process the mental changes take place. If in doubt of this claim, ask any psychiatrist or psychologist what occurs mentally when their patients do not experience the predicted outcome from therapy. If the practitioners cannot answer this question, they do not have a precise scientific understanding of what occurs mentally when their patients achieve mental changes through therapy. Until now, I have not obtained a sufficient scientific answer to this question.

The rationale for these phenomena is that the objects of psychiatric focus are not sufficiently valid expressions of mental torment as a mental experience. Descriptions of deviant behavior ${ }^{[17]}$ information about the client's reactions, interpretations of the mental disorder ${ }^{[18]}$ descriptions of social relationships ${ }^{[7,19]}$ and diagnoses prescribed in DSM IV ${ }^{[20]}$ and ICD-10 ${ }^{[21]}$ are not direct expressions of how psychological pain is mentally experienced. Psychological and psychiatric knowledge about how the mental disorder is experienced is therefore still dominated by non-falsifiable but still qualified, guesses ${ }^{[22]}$. We should focus on how the experience of psychic pain appears to yield scientifically valid knowledge about mental torment as a mental experience.

\subsection{Challenges Related to Therapeutic Research}

Findings in Meta-analyses on the aspects of successful therapy ${ }^{[25]}{ }^{[26]}$ contain systematic errors with respect to validity. Such research is quasi-scientific, as it uses scientific methods on insufficiently valid psychological objects as indicators of mental change when investigating therapeutic factors which are responsible for the patient's outcome of therapy. Scientists, therefore, do not have precise knowledge about the factors that are responsible for therapeutic results. The results from meta-research ${ }^{[24-26]}$ which are almost completely accepted in the fields of therapy research and psychology, except from some critical reflections ${ }^{[25,27,28]}$ showing that the specific therapeutic methods only count for $15 \%$ of therapeutic results ${ }^{[23,26]}$ may be wrong, with the conclusion that we should obtain more valid scientific knowledge about what works in therapy and should redefine our understanding of the term "mental change". The logical analysis described in this article may therefore be used both as a supplement to or as a basis for the critique of the weaknesses in the meta-research. This analysis alone may justify this article. Nevertheless, results from meta-research (ibid) regarding factors which are responsible for the therapeutic results do serve a positive function; namely, they describe important prerequisites for achieving changes through treatment.

\section{The logical Method}

I deconstructed mental disorders and analyzed the different elements in the immediately experienced emotions. The method consisted of four logically based considerations.

\subsection{Specific Psychological Material Must Constitute the State of Well-Being or Distress}

In the field of psychology, this material has different names, such as gestalts, traumas, anxiety, object relations, internal representations, and dysfunctional thoughts. However, these designations do not indicate how these sensations are experienced mentally, as they are scientific abstractions. These elements are described here as "external empiricism". The following question is therefore still unanswered: What is the psychological material that constitutes the mental experiences of, for example, anxiety, trauma, and joy? This material is termed here as "the inner empiricism". 


\subsection{The Psychic Material must Consist of Something Internal and be Limited to Psychological Elements}

The material can only consist of feelings, inner sensory experiences, thoughts (words and phrases), and biological elements that anchor the other elements. My assertion is that these elements continuously anchor mental states and emotions. These elements are named the bio-psychological elements because they are both mental elements containing emotions (psyche) and biological elements that anchor these emotions.

The modalities of mental experience are composed of visual, auditory, and kinesthetic impressions, as well as taste and smell. My findings, through an analysis of 13425 statements between the therapist (me) and the patients, obtained from a total of 11 consultations, show that the experienced modalities are emotions and that these elements control emotional experiences. Access to these items can be adjusted during therapy, thereby leading to psychological change. Some example scenarios are as follows: if the client makes an uncomfortable "black mental experience" lighter, makes an uncomfortably large visual mental picture smaller, or moves an uncomfortably close sensory experience further away, most patients will experience an immediate shift in their mental state. These findings are in agreement with those of Bandler and McDonald ${ }^{[29]}$.

The emotional elements: The emotional elements are bodily sensations. Emotional experiences are, based on my findings, a result of access to modalities and linguistic elements that hold emotions ${ }^{[13]}$. Emotions are understood here as signals, not as first causes, of mental well-being or distress. The emotional elements are not available for observation by the client, but they can be accessed if the client can translate or transform these feelings, through language, into sensory experiences such as visual and kinesthetic elements. This process may occur without reducing the intensity of the emotions. The client's emotions can thus be accessible to the therapist and can then be changed. Painful mental sensory experiences and painful linguistic elements, such as specific words, phrases, and metaphors, can be changed during the therapy process into modalities and linguistic elements that invoke more pleasant feelings, and an improved mental state for the client.

\subsection{The Linguistic Elements}

The linguistic elements, such as words, phrases, and metaphors, are emotions and are embedded with emotional qualities. Linguistic elements are therefore not only information about feelings or situations; they are rooted in biology at the same time that they are thought and spoken. The client's immediate experience of his or her own emotions is therefore available to the therapist in the same moment by listening to the client's words. Through certain interventions, the therapist can then make the patients change the immediate intensity and quality of the modal and linguistic elements that contain the emotions, with the result that the patients instantly achieve emotional changes. These immediate emotional changes can then be prolonged by using more interventions that have the same effects as the first interventions. Therapeutic phrases (words) may therefore be used as a method for changing the emotions that are embedded in certain words. The options for mental change through the use of words, in this manner of understanding, are extensive but must be adapted to the client's modal preferences, mental capacity, and needs.

\subsection{The Biological Elements}

Concurrent with this change in the modal and linguistic elements a change will occur in the neuro-biological condition. Every word, every inner sensory experience, and every feeling reflects a neuro-biological condition in the same moment that the words are expressed, the sensory experiences are perceived, and the feelings are experienced ${ }^{[13]}$. Every mental change thus reflects a change in the mentally related biological condition, and these biological changes anchor the emotional changes. The following are examples of emotional experiences that could prompt mental and/or biological changes: A posttraumatic incest experience from childhood was described as a dark, heavy, brown black lump of lead with spikes that rotated in the stomach at the solar plexus. Performance anxiety in a musician was experienced as a feeling of being unable to see and read the notes. The client stated that, "It was like there was a mist between me and the notes." A feeling of resignation over a persistent problem was described as "a mountain" that the client was never able to climb.

What is common among these examples? Unpleasant unspecified emotions are translated here by language into visual and auditory modalities by the patients, which reflect a biological condition. Through this process, the connection between the client's emotions, language, modal experiences, and biological state is revealed. This process renders the client's emotions accessible and, therefore, changeable by the therapist.

The consequence of the above mentioned process is that all emotional states are caused and controlled by the conscious or unconscious access to modalities and linguistic elements that hold the client's emotions. The changing of emotions therefore requires that we change the modalities and/or the linguistic elements that store and trigger these emotions. When the therapist, through verbal interventions, changes the elements that hold these emotions in a specific situation, the client will not only experience an emotional change but will also immediately change the way he or she uses language in the situation that is being focused on in the therapeutic process. A change in the biological condition will also occur, which reflects and anchors the emotional experiences, inner sensory experiences, and linguistic changes. 


\section{A Definition of Mentally Rooted Psychiatric Distress and Mental Change}

These observations led to the following definition of mentally anchored psychological disease: every momentarily experienced mentally rooted disorder can be defined as a result of the immediate access to bio-psychological elements that store the client's emotions related to the mental disorder, whereas a long-lasting mental disorder can be defined as access to these items over a long period of time. Considering this definition, the challenge, when one wants to study what constitutes the experience of immediate psychological pain, consists of mapping the client's modal experiences and linguistic elements, which are connected to the client's emotions.

Because any immediate experience of psychic pain is the result of access to mental elements that store this pain, a mental change must follow changes in these items. A permanent change in the psychological disorder must therefore be a consequence of a permanent change in the client's access to the bio-psychological elements that hold the psychological pain.

\section{Logical Considerations}

\subsection{The Arguments}

A study on burnout led to extensive amounts of information about this psychological condition. The conclusion was that burnout or any other mental state is a result of some psychic material that is coupled with or decoupled from the psyche in a given moment or over time. The material that is connected to or disconnected from the psyche is either positively or negatively psychologically charged. In addition, this mental material must be related to the past, present, or future.

This structure results in a total of 12 possible main mental states in each moment, namely 6 positively and 6 negatively charged psychological mental states. The 6 positive conditions must be the result of positive psychic material being connected to the mental state. This material could stem from the past (a pleasant experience), from the present (an immediate joy), or it may be connected to the future (a feeling of hope). At the same time, some negatively charged material, also from the past, the present, or the future, will be disconnected from the consciousness. The 6 negatively charged mental states indicate that negatively charged psychic material is connected to the mental state. This material could also stem from the past (a trauma) or the present (dysfunctional thoughts), or it could be connected to the future (catastrophic anxiety). At the same time, some positively charged psychic materials are disconnected.

My conclusion is that all mental states can be categorized into 1 of these 12 possible mental states in every moment, although the mental states may change from moment to moment.
Given that we only have 12 major mental conditions, we logically have only 12 main forms of mental change in every moment: 6 that lead to well-being and 6 that lead to the experience of mental distress. The 6 positive patterns of change indicate that positively charged psychological material is connected to the mental state, while, at the same time, negatively charged mental material is disconnected, through therapeutic interventions, in the same moment. The 6 negative forms of mental change, which lead to psychological distress, indicate that negatively charged mental material from the past, present, or future becomes connected to the psyche at a specific moment. At the same time, positive psychological material associated with the past, present, or future is disconnected from the mental state, also as a result of the verbal interventions by the therapist.

\subsection{Some Examples}

A client told me that she pictured herself sitting on the floor with a doll. The doll was big, and she was small. The doll said unpleasant things and commanded the girl to do things in a stern voice. Based on the girl's wishes and my interventions, the girl made the doll smaller in her mental picture, which means that I disconnected the negatively charged visual material in such a way that the doll became a regular doll, and the girl became connected to a more positive mental state. The doll's voice was also changed from a stern voice to a more friendly voice, i.e., positively charged mental material. The girl immediately felt much better. The hallucination disappeared, and we continued the treatment as before. We did not try to understand the mental processes that led to the hallucination; we only changed the negatively charged sensory experiences that anchored the experience of mental distress.

A client was mentally fatigued from experiencing the same mental problems for a long period of time. This situation meant that negative psychic material was connected to the mental state. As mentioned before, the client experienced the feeling of despair as a mountain he could never overcome. I "requisitioned" a helicopter, mentally, which was consistent with the client's linguistic logic and allowed the client to "fly up" over the mountain. In this situation, the client experienced a positive sensation in the form of a positively charged visual element. High above the mountain, the client exclaimed that he now could overlook the problem and that the problem seemed to be smaller and therefore less serious than before.

What occurred mentally in these examples?

The patients experienced mental pain in these situations, indicating that some negatively charged mental material was linked to the mental state. When asked by the therapist about how the feeling was experienced, the patients translated the unpleasant feelings to sensory elements bearing the same degree of emotional pain through language. These items are now regarded as a direct expression of the patients' emotions.

The modalities and linguistic elements that are responsible for the unpleasant emotions are then 
disconnected through my interventions, whereas positively charged modalities and positive linguistic elements are added to the mental state. The therapeutic language is based on the words and metaphors used by the patients to describe their mental pain. Uncoupling and decoupling psychic material always occurs in the present. In approximately 90 minutes, approximately 100 change processes of this type can occur. The sums of the small changes lead to the overall psychological change in each consultation.

\section{Some Answers to a Crucial Question}

How is it possible to continuously reduce mental disorders that have lasted for years just in some few hours by changing the client's access to the negatively charged mental elements and by placing the clients in a situation where they produce mental elements bearing psychologically wellbeing through the therapy?

The first answer is that the new mental elements do have the same properties as the negatively charged ones. One of these properties is stability. One reason for the stability of the mental disorders is the stability in the mental elements bearing the mental pain. But this stability also applies to the new positive mental elements being developed through therapy, and which are giving the clients access to psychological wellbeing. The mental experiences and the feeling of mastering or wellbeing can therefore be as stable as the former mental disorder. Another reason stems from some peculiar experiences, which have been tested through thousands of interventions. It looks like that if we destroy the mental elements holding the mental pain, the clients reduce the tendency to produce, reinforce or to get access to mental negatively charged material. And it follows that the more the clients are getting access to positive mental material; the clients will produce mental material with the same qualities in his ordinary life. These experiences also explain why it may be difficult for some clients to change or reduce the mental disorder through therapy. The one reason is that that the new mental elements are weaker or less intense than the existing ones. The second is that the client can produce or get access to more negatively charged mental material in his daily life than the therapist can reduce in the small hours of therapy. And the third reason may be that the amount of negatively mental material that must be changed reduced or destroyed may be to much. But this moments are only telling that the therapist have more work to do. My experience is that almost all psychological disorders may be changed through therapy.

\section{A Logic-Based Allegation on Damasios Errors}

Damasio, the Portuguese-American neurologist, has written some interesting books on the connection between neurological processes and emotions, mostly based on investigations of the damaged brain ${ }^{[30,31]}$. His analyses are both profound and inspiring, but our conjecture is that he will not succeed in finding the observable link between brain processes and emotions until he precisely understands the psyche and mental processes; that is, he will not understand mental processes without altering his focus from the damaged brain and the results from brain scanning to real-life mental processes. We believe that this problem exists across all neuroscientific studies of this nature. Without a scientifically valid understanding of how emotional states are mentally constructed and without understanding when during therapy the client experiences a mental change, the scientists will not be able to interpret the results from different methods of brain scanning. We cannot draw scientific inferences from the results of the neurological research on emotional states without a scientifically falsifiable and controllable knowledge of mental and emotional states.

\section{Conclusions}

Every mental state is composed of modalities and linguistic and emotional elements that are rooted in mentally related biological elements. Mental pain can therefore be observed by focusing on the modalities and linguistic elements that anchor this pain. Mentally rooted disorders are, in principle, derived from the same mental elements, such as joy, motivation, skillfulness, aggression, love, and hate, and these strongly different emotions or abilities can be altered and developed through the same types of interventions, by altering the modalities and the linguistic elements that are connected to the psychological distress. These processes of mental change are similar in nature regardless of whether patients are suffering from mental pain and distress or are functioning well but want to improve certain skills or their personality. This situation makes it possible to treat mentally anchored disorders in a predictable manner and to do so with limited information about the client's situation and the context in which the mental disorders are unfolding. But we have to be aware of the possibility that the therapist may conserve, reinforce or produce mental elements bearing mental pain as a consequence of the way he or she is using language, which will prolong the mental disorder.

The brain processes are extremely complex, but the psyche and the mental rooted disorder are much simpler in its composition, and are much easier to alter through verbal interventions than psychologists and therapists believe, and that is presented through psychology and psychiatry. Treatment may still be a complex task.

\section{Acknowledgements}

My thanks is to Anne-Grethe Tuseth who introduced me to the field of family therapy and to the social constructionist therapy traditions, and to Barry Duncan for inspiring talks about what works in therapy, in an important period of my work. My thanks also go to Edvard Befring, who encouraged my work in a period still characterized by 
uncertainty.

\section{References}

[1] Watzlawick P, Bevin J \& Jackson D. Pragmatics of human communication. Norton: NY, US, 1967.

[2] Watzlawick P, Weakland JH, \& Fisch R. Forandring: prinsipper fra psykoterapien. Oslo: Gyldendal 1980.

[3] Shazer, S. Clues: Investigating Solutions in Brief Therapy. W. W. Norton \& Company: NY, US, 1988.

[4] Shazer S. Keys to Solution in Brief Therapy. W. W. Norton \& Company: NY, US, 1985.

[5] White M. \& Epston D. Narrative Means to Therapeutic Ends. W. W. Norton \& Company: NY, US 1990.

[6] White M. \& Epston D. Re-Authering Lives. Interviews \& Essays. Dulwich Centre Publications: Adelaide, Australia, 1995.

[7] Andersen T. The Reflecting Team. Dialogue and meta-dialogue in clinical work. Family Process 1987; 26, 415-428.

[8] Anderson H. Conversation, Language, And Possibilities: A Postmodern Approach To Therapy. Basic Books: NY, US, 1997.

[9] Bandler R. Using Your Brain for a Change. Real People Press: Utah, US, 1988.

[10] Bandler R \& Grinder J. Frogs into Princes: Neuro Linguistic Programming. Real People Press: Utah, US, 1979.

[11] Bandler R \& Grinder J. Reframing: Neuro-Linguistic Programming and the Transformation of Meaning. Real People Press: Utah, US, 1982.

[12] Glaser B \& Strauss A. The Discovery of Grounded Theory: Strategies for Qualitative Research. Aldine Transaction: Chicago, US, 1967.

[13] Dammen Ph. En undersøkelse av psykisk plage og psykisk endring med utgangspunkt $\mathrm{i}$ enkelte endringsprosesser. Et bidrag i utvikling av en vitenskapelig tilnærming til endring av psykisk forankrede plager. En studie gjennomført med et kombinert design. (A study of psychological distress and mental change as a result of treatment. The work is a contribution to the development of a scientific approach to change mental rooted problems. It is a study conducted with a mixed design.) Akademika forlag: Oslo, Norway, 2013.

[14] Wittgenstein L. Tractatus Logico-Philosophicus. Routledge: London, UK, 2001.

[15] Popper K. The Logic of Scientific Discovery. Routledge Classics, UK 2002.

[16] Derrida J. Deconstruction Engaged: The Sydney Seminars. Power Publications: Sydney, Australia, 2001.
[17] Hawton K, Salkovskis PM, Kirk J, Clark DM. Cognitive Behavior Therapy for Psychiatric Problems. A practical guide. Oxford University Press: Oxford, UK, 1998.

[18] Vetlesen AJ \& Stänicke E. Fra hermeneutikk til psykoanalyse. Muligheter og grenser i filosofiens møte med psykoanalysen. Ad Notam Gyldendal: Oslo, Norge, 1999.

[19] Gergen K. The Saturated Self: Dilemmas Of Identity In Contemporary Life. Basic Books: 1992.

[20] Helsedirektoratet. ICD-10: den internasjonale statistiske klassifikasjon av sykdommer og beslektede helseproblemer $\square$ : systematisk del, alfabetisk indeks.: Helsedirektoratet. Oslo , Norway, 2011.

[21] APA. Diagnostic and Statistical Manual of Mental Disorders: DSM-IV. American Psychiatric Association: US, 2011.

[22] Popper KR. Conjectures and Refutations: The Growth of Scientific Knowledge. Routledge projects. Education for Information 2002; 22, 63-75.

[23] Duncan BL, Miller SD, Wampold BE \& Hubble MA. The Heart and Soul of Change. Delivering What Works in Therapy. American Psychological Association: Washington, US, 2009.

[24] Lambert J, Bergin FJ \& Garfield SL. Bergin and Garfield's Handbook of Psychotherapy and Behavior Change. Wiley: New York, US 2004.

[25] Lambert MJ \& et al. Enhancing psychotherapy outcome via providing feedback on Client progress: A Replication. Clinical psychology and psychotherapy 2002; 9, 91-103.

[26] Lambert MJ. Psychotherapy outcome research: Implications for integrative and eclectic therapists. In Norcross JC \& Goldfried MR (Eds.). Handbook of Psychotherapy Integration (pp. 94-129). Basic Books, New York, US, 1992.

[27] Norcross JC. Dispelling the Dodo Bird verdict and the exclusivity myths in psychotherapy. Psychotherapy Theory, Research, Practice, Training 1995; 32, 500-504.

[28] Rønnestad MH. Evidens-baced pratice in psychology. Journal of the Norwegian Psychological Association 2008; 45, nr.4 p.444-454.1 (http://www.psykologtidsskriftet. no/index.php?seks_id $=125210 \& \mathrm{a}=$ ).

[29] Bandler R \& McDonald W. An Insiders Guide to Sub-Modalities. Metapublications: Ca, US, 1998.

[30] Damasio A. Følelsen av hva som skjer: kroppens og emosjonenes betydning for bevisstheten. Pax: Oslo, Norway, 2002. Translated from: The Feeling of What Happens: Body and Emotion in the Making of Consciousness. Amazon: Ny, USA, 1999.

[31] Damasio A. Descartes' feiltagelse: fornuft, følelser og menneskehjernen. Pax: Oslo, Norway, 2004. Translated from: Descartes' Error. Emotion, Reason, and the Human Brain. Amazon, NY, USA, 2000. 